\title{
A REVIEW OF REFRIGERANT MALDISTRIBUTION
}

\author{
S.H. Tang ${ }^{1}$, M.H. Chng ${ }^{12^{*}}$ and W.M. Chin ${ }^{2}$ \\ ${ }^{1}$ Faculty of Engineering, Universiti Putra Malaysia, 43400 UPM Serdang, \\ Selangor Darul Ehsan. Malaysia \\ *Email: chngminghui88@gmail.com \\ Phone: +60122310614 \\ ${ }^{2}$ O.Y.L. R\&D Centre Sdn Bhd, Lot 60334, Persiaran Bukit Rahman Putra 3, Taman \\ Perindustrian Bukit Raman Putra, 47000 Sungai Buloh, Selangor, Malaysia.
}

\begin{abstract}
In recent years, conservation of energy has become a challenging issue in air-conditioning applications. In order to overcome this issue, many researchers have recommended the use of a Parallel Flow Condenser and a low Global Warming Potential and Ozone Depletion Potential refrigerant, such as R32, in air conditioning systems. However, PFC faces the critical challenge of flow maldistribution in the tubes. This literature review mainly examines the refrigerant maldistribution problem which has been investigated by previous researchers. It was found that many of the researchers did not properly analyse the influence of flow maldistribution profiles on the performance degradation of heat exchangers. In order to have a comprehensive analysis of tube-side maldistribution in Parallel Flow microchannel heat exchangers, it is recommended that the influence of the higher statistical moments of the probability density function of the flow maldistribution profiles on performance degradation be quantified. Additionally, R32 maldistribution should be analysed and compared with R410A, which is the current commonly used refrigerant in air conditioning units. Moreover, in order to have a realistic simulation of the effect of refrigerant flow maldistribution profiles on performance degradation of heat exchangers, the effect of superheat and sub-cooling must be analysed.
\end{abstract}

Keywords: Refrigerant maldistribution; microchannel heat exchangers; parallel flow condenser.

\section{INTRODUCTION}

As we are moving forward in the twenty-first century, conservation of energy has become a challenging issue. It is vital for our country, Malaysia, to move forward and become a "Green Country". In order to achieve this target, it is necessary to reduce power consumption and improve the energy efficiency of household appliances, which include heating, ventilation and air-conditioning (HVAC) systems which consume approximately $50 \%$ of total electricity consumption in a building [1]. Due to this, new designs of heat exchangers have been implemented to increase heat transfer performance. Among them, the microchannel heat exchanger offers superior advantages such as a compact size, a large heat transfer surface area, light weight, and low cost. When it is used as a condenser in an air-conditioning unit, it is commonly called a Parallel Flow Condenser (PFC). Additionally, 
various types of refrigerants have been tested and are in use as the heat transfer medium in air-conditioning systems to reduce power consumption. Among these, the hydrofluorocarbon (HFC) R32 refrigerant is able to meet the requirements as an excellent heat transfer medium which has good thermo-physical properties with zero Ozone Depletion Potential (ODP), low Global Warming Potential (GWP) and high energy efficiency characteristics. However, the PFC faces a critical challenge of refrigerant flow maldistribution. This is due to the fact that the PFC has many "circuits" compared with a conventional fin-tube heat exchanger. Thus, the refrigerant maldistribution problem in the PFC must be analysed in greater detail to arrive at an optmum refrigeration cycle design which gives excellent power savings to the air-conditioner.

\section{The Current Trend in Heat Exchangers}

The heat exchanger is a vital component of the air-conditioning unit. It is used to transfer thermal energy between two or more fluids. There are various kinds of heat exchanger, such as a shell-and-tube heat exchanger, automobile radiators, a plate-fin heat exchanger, a fin-tube heat exchanger, a microchannel heat exchanger, etc. Among all the heat exchangers, the compact heat exchanger offers the superior advantage of having a large heat transfer surface area per the unit volume of the exchanger, which results in reduced space, weight, support structure and footprint, energy requirements, cost, improved process design and plant layout and processing conditions [2]. Additionally, the compact heat exchanger is able to reduce the amount of refrigerant inside an air conditioner. A small charge of low GWP and ODP refrigerant will reduce the total leakage, thus reducing the influence on global warming [3].

With current manufacturing technology, micro-size tubes with high precision can be produced in large quantities and at low cost. The introduction of microtechnology has highly encouraged the development of a more advanced compact heat exchanger, i.e. the microchannel heat exchanger. Moreover, the necessary minimisation of capital investment and improvement of adaptability of components has led to the rapid development of the research on a microchannel heat exchanger, especially the PFC, and its applications in many areas [4]. Dang and Teng [5] indicated that the microchannel heat exchanger is able to increase the performance and efficiency of an air conditioner [5]. Li, Wang [6] have also stated that the microchannel heat exchanger is a highly efficient air-cooled heat exchanger [16]. However, the microchannel heat exchanger has some disadvantages, such as a high pressure drop, and manufacturing problems including the large relative tolerance of the channels' thickness. This contributes to uneven flow distribution, which affects airconditioner performance.

\section{The Current Trend in Refrigerants}

Refrigerant is used as the heat transfer medium in air-conditioning systems. In the twentieth century chlorofluorocarbons (CFCs) such as R12 was widely used in air-conditioning system applications, and was recognised as an excellent heat transfer medium. This is due to the superior thermo-physical properties such as non-flammability, non-toxicity, high thermal conductivity, and chemical stability [7]. However, the chlorine atoms in CFCs have a major impact on ozone depletion. Karagoz, Yilmaz [7] indicated that chlorine atoms 
liberated from CFCs act as catalysts in ozone depleting reactions [7]. Strong UV light breaks apart the $\mathrm{CFC}$ molecule and releases chlorine atoms. Then, the chlorine atoms in the stratosphere attack the ozone layer by remove an atom from the ozone molecule, reducing it to an oxygen molecule [8]. Therefore, CFCs such as R12 have been phased out in developed countries since 1996 [8]. Hydrochloroflourocarbons (HCFC) with a lower ODP, such as R22, have been recommended to replace CFCs. Since 2010, R22 had been phased out in developed countries due to its ozone depletion characteristics. Searching for a replacement for R22 has intensified in recent years. Presently, R410A, which is a hydrofluorocarbon (HFC) refrigerant, has been identified as one of the alternative replacements for R22 in air-conditioning system applications. However, R410A still has a relatively high GWP. Fluorocarbon is a greenhouse gas which has a major impact on the problem of global warming. The leakage of R410A from air conditioners increases the concentration of greenhouse gases in the atmosphere, causing the amount of absorbed infrared radiation to increase, which leads to increased atmospheric temperatures and consequent long-term climate change [8]. In reality, none of the existing refrigerants can achieve good thermo-physical properties with zero ODP, zero GWP, high energy efficiency characteristics, non-flammability, non-toxicity, miscibility with traditional compressor mineral oil, and compatibility with common materials. Therefore, refrigerants which have zero ODP, low GWP and good thermo-physical properties, such as R32, are recommended as the heat transfer medium in air-conditioning systems.

Many researchers have recommended using R32, which is also known as difluoromethane, as the replacement refrigerant. This is because R32 has a lower GWP of 675 compared with R410A, which has a GWP of 1900. Xu et al. claimed that the capacity and coefficient of performance (COP) improvements using R32 can reach up to $10 \%$ and $9 \%$, respectively, compared with R410A [9]. They also concluded that R32 is an excellent alternative compared to R410A in terms of performance and environmental issue [9]. Therefore, the characteristics of R32 should be analysed and compared with R410A. Theoretically, R32 has a higher flow velocity compared to R410A at the same mass flow rate. This is due to its lower density. If R32 is employed as the refrigerant in a heat exchanger, the effect of flow maldistribution will become an unknown. Thus, a comprehensive analysis of R32 maldistribution must be conducted. However, R32 has a disadvantage, i.e. it is slightly flammable. Table 1 shows the basic properties of R32.

Table 1. Basic properties of R32 [9].

\begin{tabular}{lcc}
\hline \multicolumn{1}{c}{ Property } & Unit & R32 \\
\hline Composition & - & Pure fluid \\
Molecular weight & $\mathrm{g} \mathrm{mol}^{-1}$ & 52 \\
Critical pressure & $\mathrm{MPa}^{\circ}$ & 5.78 \\
Critical temperature & ${ }^{\circ} \mathrm{C}$ & 78.1 \\
Critical density & $\mathrm{kg} \mathrm{m}^{-3}$ & 424.1 \\
Normal boiling point & ${ }^{\circ} \mathrm{C}$ & -51.7 \\
GWP & - & 675 \\
\hline
\end{tabular}




\section{REFRIGERANT MALDISTRIBUTION}

Theoretically, most designers assume that the flow distribution in a heat exchanger is uniform. However, in reality, these assumptions are generally not realistic where flow maldistribution occurs in all types of heat exchanger. In fact, flow maldistribution reduces the thermal performance of a heat exchanger and increases the pressure drop. Marchitto et al. have also indicated that uneven distribution in heat exchangers is a cause of reduction in both thermal and fluid-dynamic performances [10]. Jiao, Zhang [11] have indicated that flow maldistribution can be classified into two types, i.e. gross maldistribution and passageto-passage maldistribution [11]. Passage-to-passage flow maldistribution occurs due to manufacturing tolerances, fouling, and frosting of condensable impurities, while gross flow maldistribution is mostly related to improper heat exchanger entrance/exit configuration, such as the poor design of the header and distributor configuration [11]. The flow maldistribution problem becomes even worse in compact heat exchangers such as the PFC, which has multiple small channels. This is due to the nominally small channel diameters and the relatively large tolerance of manufactured channel spacing [12]. Hence, the effects of the maldistribution profile in various kinds of heat exchanger, especially the PFC, should be quantified and analysed in order to design a better heat exchanger.

\section{Analysis of the Refrigerant Maldistribution Problem}

There are many studies which have investigated the effects of flow maldistribution on plate-fin and fin-tube heat exchangers. However, there is not much information on the effects of tube-side maldistribution in PFC microchannel heat exchangers. Table 2 shows some of the previous works related to flow maldistribution done by other researchers. The first mathematical method to determine the effectiveness of the crossflow heat exchanger accounting for the effect of two-dimensional nonuniform fluid flow distribution was developed by Chiou [13]. He has indicated that nonuniform fluid flow distribution causes heat exchanger performance deterioration. Rabas [14] conducted an experiment to examine the effect of tube-side maldistribution on the thermal performance of the condensers used in multistage flash (MSF) distillation plants [14]. He found that tube-side maldistribution does not impair the thermal performance of long-tube lengths and low-effectiveness value heat exchangers. However, the tube-side maldistribution cannot be neglected for short-tube length and high-effectiveness heat exchangers and the thermal performance can be reduced by as much as $10 \%$. Chwalowski, Didion [15] performed a simulation and experimental study of an evaporator operating with different air velocities caused by different installations and found that there was a capacity difference of $30 \%$ in extreme cases [15]. David et al. studied the effects of non-uniform airflow on the performance of a typical fintube type evaporator by using Refrigerant 134a as the working fluid [16]. From their experiment, it appeared that a uniform flow does not necessarily give the best heat transfer performance [16]. Although there was non-uniform air flowing through a single-circuit R134a evaporator (without significant water vapour condensation), the heat exchanger performance was slightly better than uniform flow. Lee et al. executed a simulation study of R22 and R407C evaporators with non-uniform air and refrigerant distributions and the results showed that the level of capacity degradation was affected by the refrigerant circuitry design and air velocity profile relative to that circuit [17]. However, they indicated 
that the capacity of the evaporator showed a greater sensitivity to air maldistribution than to refrigerant maldistribution.

Table 2. Previous work done by other researchers.

\begin{tabular}{|c|c|c|c|c|c|}
\hline Author & Fluid & Application & $\begin{array}{l}\text { Heat } \\
\text { Exchanger }\end{array}$ & Method & Comments \\
\hline [13] & $\begin{array}{l}\text { Various } \\
\text { kind of } \\
\text { fluids }\end{array}$ & $\begin{array}{l}\text { Industrial } \\
\text { application }\end{array}$ & $\begin{array}{l}\text { Crossflow } \\
\text { heat } \\
\text { exchanger }\end{array}$ & Numerical & $\begin{array}{l}\text { Investigate non-uniform fluid flow } \\
\text { distribution }\end{array}$ \\
\hline [14] & Water & $\begin{array}{l}\text { Multistage } \\
\text { flash } \\
\text { distillation } \\
\text { plant }\end{array}$ & $\begin{array}{l}\text { Cross-flow } \\
\text { Heat } \\
\text { Exchanger }\end{array}$ & Experimental & $\begin{array}{l}\text { Examine the effect of tube-side } \\
\text { maldistribution }\end{array}$ \\
\hline [15] & Air & $\begin{array}{l}\text { Industrial } \\
\text { application }\end{array}$ & $\begin{array}{l}\text { Plate-fin } \\
\text { Heat } \\
\text { Exchanger }\end{array}$ & Experimental & $\begin{array}{l}\text { Experimental study of heat } \\
\text { exchanger performance with } \\
\text { different air flow }\end{array}$ \\
\hline [16] & R134a & $\begin{array}{l}\text { Air } \\
\text { conditioning }\end{array}$ & $\begin{array}{l}\text { Fin-tube Heat } \\
\text { Exchanger }\end{array}$ & Experimental & $\begin{array}{l}\text { Study the effect of non-uniform air } \\
\text { flow }\end{array}$ \\
\hline [17] & $\begin{array}{l}\mathrm{R} 22 \text { and } \\
\mathrm{R} 407 \mathrm{C}\end{array}$ & $\begin{array}{l}\text { Industrial } \\
\text { application }\end{array}$ & & Numerical & $\begin{array}{l}\text { Simulation study on non-uniform } \\
\text { air and refrigerant distribution }\end{array}$ \\
\hline [18] & $\begin{array}{l}\text { All kinds } \\
\text { of fluids }\end{array}$ & $\begin{array}{l}\text { Cryogenic } \\
\text { plants }\end{array}$ & $\begin{array}{l}\text { Plate-fin } \\
\text { Heat } \\
\text { Exchanger }\end{array}$ & Numerical & $\begin{array}{l}\text { Use finite element model to } \\
\text { analyse the effect of two } \\
\text { dimensional nonuniform flow }\end{array}$ \\
\hline [20] & Water & $\begin{array}{l}\text { Electric } \\
\text { heater }\end{array}$ & $\begin{array}{l}\text { Electrical } \\
\text { heater }\end{array}$ & Experimental & $\begin{array}{l}\text { Investigate the effect of flow } \\
\text { maldistribution on heat exchange } \\
\text { performance }\end{array}$ \\
\hline [19] & $\begin{array}{l}\text { All kinds } \\
\text { of fluids }\end{array}$ & $\begin{array}{l}\text { Cryogenic } \\
\text { plants }\end{array}$ & $\begin{array}{l}\text { Plate-fin } \\
\text { Heat } \\
\text { Exchanger }\end{array}$ & Numerical & $\begin{array}{l}\text { Analysis of the combined effects of } \\
\text { two-dimensional longitudinal heat } \\
\text { conduction and nonuniform inlet } \\
\text { fluid flow and temperature } \\
\text { distribution }\end{array}$ \\
\hline [11] & Water & $\begin{array}{l}\text { Cryogenic } \\
\text { plants }\end{array}$ & $\begin{array}{l}\text { Plate-fin } \\
\text { Heat } \\
\text { Exchanger }\end{array}$ & Experimental & $\begin{array}{l}\text { Investigate the effect of inlet pipe } \\
\text { diameter on flow maldistribution }\end{array}$ \\
\hline [21] & $\begin{array}{l}\text { Air, } \\
\text { refrigerant } \\
\text { and water }\end{array}$ & $\begin{array}{l}\text { Air } \\
\text { conditioning }\end{array}$ & $\begin{array}{l}\text { Fin-tube Heat } \\
\text { Exchanger }\end{array}$ & Experimental & $\begin{array}{l}\text { Investigate the capacity } \\
\text { degradation due to non-uniform } \\
\text { refrigerant and air flow } \\
\text { distributions }\end{array}$ \\
\hline [22] & $\begin{array}{l}\text { Refrigerant } \\
\text { and water }\end{array}$ & $\begin{array}{l}\text { Industrial } \\
\text { application }\end{array}$ & $\begin{array}{l}\text { Multiple } \\
\text { parallel tube } \\
\text { heat } \\
\text { exchanger }\end{array}$ & Experimental & $\begin{array}{l}\text { Investigate two-phase flow } \\
\text { distribution }\end{array}$ \\
\hline [23] & Air & $\begin{array}{l}\text { Cryogenic } \\
\text { plants }\end{array}$ & $\begin{array}{l}\text { Plate-fin } \\
\text { Heat } \\
\text { Exchanger }\end{array}$ & Experimental & $\begin{array}{l}\text { Investigate the effect of entrance } \\
\text { configuration changes on flow } \\
\text { maldistribution }\end{array}$ \\
\hline [24] & Nitrogen & $\begin{array}{l}\text { Cryogenic } \\
\text { plants }\end{array}$ & $\begin{array}{l}\text { Plate-fin } \\
\text { Heat } \\
\text { Exchanger }\end{array}$ & Numerical & $\begin{array}{l}\text { Study the effect of header } \\
\text { configuration on flow } \\
\text { maldistribution }\end{array}$ \\
\hline [10] & $\begin{array}{l}\text { Air and } \\
\text { Water }\end{array}$ & $\begin{array}{l}\text { Marine and } \\
\text { industrial } \\
\text { application }\end{array}$ & $\begin{array}{l}\text { Compact } \\
\text { Heat } \\
\text { Exchanger }\end{array}$ & Experimental & $\begin{array}{l}\text { Investigate some } \\
\text { phenomenological aspects of two- } \\
\text { phase distribution }\end{array}$ \\
\hline
\end{tabular}


Table 2. Continued

\begin{tabular}{|c|c|c|c|c|c|}
\hline Author & Fluid & Application & $\begin{array}{l}\text { Heat } \\
\text { Exchanger }\end{array}$ & Method & Comments \\
\hline [26] & Water & $\begin{array}{l}\text { Cryogenic } \\
\text { plants }\end{array}$ & $\begin{array}{l}\text { Plate-fin } \\
\text { Heat } \\
\text { Exchanger }\end{array}$ & Experimental & Examine two-phase maldistribution \\
\hline [25] & R134a & $\begin{array}{l}\text { Air } \\
\text { conditioning }\end{array}$ & $\begin{array}{l}\text { Microchannel } \\
\text { Heat } \\
\text { Exchanger }\end{array}$ & Numerical & $\begin{array}{l}\text { Investigate the effect of flow } \\
\text { maldistribution on heat exchange } \\
\text { performance }\end{array}$ \\
\hline [27] & $\begin{array}{l}\text { Water and } \\
\text { Carbon } \\
\text { dioxide }\end{array}$ & $\begin{array}{l}\text { Air } \\
\text { conditioning }\end{array}$ & $\begin{array}{l}\text { Multiple } \\
\text { parallel tube } \\
\text { heat } \\
\text { exchanger }\end{array}$ & $\begin{array}{l}\text { Numerical } \\
\text { and } \\
\text { Experimental }\end{array}$ & $\begin{array}{l}\text { Numerical comparison of a } \\
\text { manifold system with two different } \\
\text { orientations }\end{array}$ \\
\hline [28] & Water & $\begin{array}{l}\text { Air } \\
\text { conditioning }\end{array}$ & $\begin{array}{l}\text { Fin-tube Heat } \\
\text { Exchanger }\end{array}$ & Numerical & $\begin{array}{l}\text { Study the effect of higher statistical } \\
\text { moments on air flow } \\
\text { maldistribution }\end{array}$ \\
\hline [12] & $\begin{array}{l}\text { Mixture of } \\
\text { ethylene } \\
\text { glycol and } \\
\text { water }\end{array}$ & $\begin{array}{l}\text { Electronic } \\
\text { cooling, etc. }\end{array}$ & $\begin{array}{l}\text { Microchannel } \\
\text { Heat } \\
\text { Exchanger }\end{array}$ & $\begin{array}{l}\text { Numerical } \\
\text { and } \\
\text { Experimental }\end{array}$ & $\begin{array}{l}\text { Investigate the effect of flow } \\
\text { maldistribution on heat exchange } \\
\text { performance }\end{array}$ \\
\hline [29] & Water & $\begin{array}{l}\text { Electronic } \\
\text { cooling, etc. }\end{array}$ & $\begin{array}{l}\text { Microchannel } \\
\text { Heat } \\
\text { Exchanger }\end{array}$ & Numerical & $\begin{array}{l}\text { Investigate the heat transfer } \\
\text { performance of non-homogeneous } \\
\text { parallel plate heat exchangers }\end{array}$ \\
\hline
\end{tabular}

Ranganayakulu, Seetharamu [18] analysed the effects of two dimensional nonuniform inlet fluid flow distribution on both hot and cold fluid sides of a crossflow plate-fin exchanger by using finite element modelling [18]. They emphasised that fluid property variations should not be neglected when analysing the flow maldistribution problem. Additionally, they found that the performance deteriorations were severe in some typical applications due to fluid flow nonuniformity. In addition, Ranganayakulu and Seetharamu [19] evaluated heat exchanger performance with the combined effects of wall longitudinal heat conduction (LHC), temperature nonuniformity (TN) and flow nonuniformity (FN) on crossflow heat exchangers with a balanced flow as well as with an unbalanced flow [19]. They found that the thermal performance variations of a crossflow compact heat exchanger due to the combined effects of LHC, TN and FN are not always negligible and the deterioration of thermal performance tend to eliminate each other in the regions of higher NTU. However, the performance deterioration tends to augment each other in the regions of lower NTU, when the LHC, FN and TN are considered together. They concluded that the design of the headers and inlet ducts significantly affects the velocity distribution approaching the face of the exchanger core and the flow distribution mainly depends on the location of the inlet duct, the ratio of the core frontal area to the inlet duct cross-sectional area, the distance of transition duct/header between the core face and inlet duct, and the shape of the headers.

Lalot, Florent [20] studied the air flow distribution of electric heaters and found that reverse flows might occured due to poor inlet header design [20]. From their findings, it was shown that gross flow maldistribution led to a loss of effectiveness of about $7 \%$ for condensers and counterflow heat exchangers, and up to $25 \%$ for crossflow exchangers [20]. They recommended installing a uniformly-perforated grid in the inlet header, which could 
make the distribution more even. Jiao, Zhang [11] investigated the effects of the inlet pipe diameter, the first header's diameter of equivalent area and the second header's diameter of equivalent area on the flow maldistribution in a plate-fin heat exchanger [11]. The experimental studies showed that the flow velocity distribution became more uniform when the first header's diameter of equivalent area was equal to the second header's diameter of equivalent area. In short, optimisation of header configuration can effectively improve the flow distribution in plate-fin heat exchangers. Two maldistributed air flow scenarios were studied by Choi et al. - one, assuming constant volumetric flow of air, and the other, assuming that the volumetric flow rate would decrease with obstructions to the air flow [21]. Their study showed that capacity degradation due to refrigerant maldistribution can be as much as $30 \%$, even when the overall evaporator superheat is kept at the target $5.6^{\circ} \mathrm{C}$, and the experiments showed a rapid decrease in capacity when superheat increased in individual circuits.

Vist and Pettersen [22] investigated the effects of vapour fraction at the manifold inlet, heating load on the heat exchanger tubes, and the diameter of the manifold and manifold inlet tube length on performance deterioration due to flow distribution [22]. They conducted an experiment with a short inlet tube to the manifold $(55 \mathrm{~mm})$ and it showed enhanced vapour and liquid distribution. Refrigerant R134a was used as a refrigerant in their experiment. Additionally, they also found that increasing the vapour fraction at the inlet of the manifold gave better a distribution of the vapour phase both in the upward and downward flow experiments. Finally, they concluded that the flow pattern at the inlet of the manifold was of great importance, and that a disturbed chaotic flow gave enhanced distribution. Wen and $\mathrm{Li}$ [23] indicated that an improved header configuration in a plate-fin heat exchanger was able to reduce performance degradation [23]. They found that when the baffle was properly installed with an optimum length, the flow distribution became more uniform. Wen et al. employed Particle Image Velocimetry (PIV) to investigate the effect of entrance configuration changes on the flow maldistribution in a plate-fin heat exchanger [24]. From their research, they found that the improved entrance configuration with punched baffle was able to reduce performance deterioration. Hence, a baffle with optimum design is recommended to improve the performance of the heat exchanger. Furthermore, Marchitto, Devia [10] indicated that the effects of the operating conditions, the headerchannel distribution area ratios, and the inlet port orifice plates exerted a strong influence on the structure of the two-phase flow pattern inside the header and therefore on the flow distribution to the channels [10]. In short, the combined use of various orifices at the inlet of the multiple channels and nozzles at the distributor inlet is able to improve flow rate uniformity in the heat exchanger over a specified range of gas and liquid inlet superficial velocities.

Brix, Kærn [25] investigated the effects of refrigerant maldistribution in parallel evaporator channels on heat exchanger performance [25]. In their research, they analysed the effect of inlet quality into the channels and non-uniform airflow with constant total mixed superheat out of the evaporator. Both cases showed that the cooling capacity of the evaporator was reduced significantly. Ahmad et al. stated that two-phase maldistribution yielded a bad thermal and hydraulic performance of compact heat exchangers with parallel flow circuits and may cause the occurrence of dry-out zones in evaporators and high liquid loading zones in condensers [26]. From their findings, they concluded that the two-phase distribution in a compact heat exchanger was affected by the flow configuration at the 
header inlet and the two-phase momentum together with the header geometry. Ablanque et al. [27] carried out a numerical comparison of a manifold system with two different orientations, i.e. horizontal manifolds with both horizontal- and upward-oriented parallel tubes, and it was found that a horizontal manifold with horizontal-oriented parallel tubes presented a more uniform distribution because the liquid and gas phases were more evenly distributed [27]. They also stated that the maldistribution situation was particularly unfavourable for two-phase flows due to the possible uneven phase split at each junction of the dividing manifold.

Chin and Raghavan [28] have indicated that any effort to analyse and predict the detrimental effects due to flow maldistribution must take into consideration the effects of higher statistical moments [28]. Without consideration of those effects, it would be difficult for refrigeration system designers to optimise the performance of the heat exchanger. In their research, they found that the kurtosis of the distribution will not affect heat exchanger performance degradation. However, the first three distribution statistical moments of mean, standard deviation, and skew have a significant effect on performance degradation. They have also concluded that distributions with low standard deviations and positive skews will tend to have lower performance degradation. Nielsen, Engelbrecht [12] have employed single blow numerical model and cyclic steady-state regenerator experiments to investigate the effect of flow maldistribution on the performance of microchannel parallel plate heat exchangers [12]. They found that as the variation of the individual channel thickness of heat exchanger increased, the actual performance of the heat exchanger decreased significantly. They concluded that the range and arrangement of various channel thicknesses affected the performance of a microchannel heat exchanger. Nielsen, Engelbrecht [29] have also indicated that maldistribution of the fluid flow significantly reduced the heat transfer performance of inhomogeneous stacks of parallel plates [29]. They found that the effective NTU was decreased as the standard deviation increased. However, large thermal conductivity and a low Reynolds number did not show a major impact on flow maldistribution [29].

\section{CONCLUSIONS}

From the results of previous works, there was no proper analysis of the influence of the statistical moments of the probability density function of the refrigerant flow maldistribution profiles on the performance degradation of heat exchangers. Flow maldistribution problems in fin-tube or PFC heat exchangers, which are commonly used in air conditioning applications, should be analysed since air conditioners consume a lot of energy. Although Chin and Raghavan [30] have analysed the influence of higher statistical moments of probability density function of the flow maldistribution profiles on the performance degradation of fin-tube heat exchangers, they did not consider tube-side maldistribution in PFC microchannel heat exchangers [30]. In fact, a mathematical model that can describe the tube-side flow distribution in PFCs has yet remained as a challenge and is a critical issue in the design of such heat exchangers. Also, the current trend of airconditioning products is moving towards using lower GWP and ODP refrigerants such as R32. Thus, the effect of flow maldistribution on PFCs with R32 refrigerant should be analysed. In order to have a more realistic simulation on the effects of refrigerant flow maldistribution on the performance degradation of heat exchangers, the superheat and sub- 
cooling effects must be analysed. Thus, a comprehensive analysis of the tube-side maldistribution in PFC microchannel heat exchangers is recommended in future studies.

\section{REFERENCES}

[1] Pérez-Lombard L, Ortiz J, Pout C. A review on buildings energy consumption information. Energy and buildings. 2008;40:394-8.

[2] Shah RK, Sekulic DP. Heat Exchangers: Thermal-Hydraulic Fundamentals and Design. Washington, DC: Hemisphere Publishing; 1981.

[3] Kew PA, Reay DA. Compact/micro-heat exchangers-their role in heat pumping equipment. Applied Thermal Engineering. 2011;31:594-601.

[4] GUPTA M. Numerical Study Of Heat Transfer Enhancement In A Plate-Fin Heat Exchanger Using Rectangular Winglet Type Vortex Generator. India: National Institute Of Technology; 2010.

[5] Dang T, Teng J-t. The effects of configurations on the performance of microchannel counter-flow heat exchangers-An experimental study. Applied Thermal Engineering. 2011;31:3946-55.

[6] Li J, Wang S, Zhang W. Air-side thermal hydraulic performance of an integrated fin and micro-channel heat exchanger. Energy Conversion and Management. 2011;52:983-9.

[7] Karagoz S, Yilmaz M, Comakli O, Ozyurt O. R134a and various mixtures of $\mathrm{R} 22 / \mathrm{R} 134 \mathrm{a}$ as an alternative to R22 in vapour compression heat pumps. Energy conversion and management. 2004;45:181-96.

[8] Bolaji B, Huan Z. Ozone depletion and global warming: Case for the use of natural refrigerant-a review. Renewable and Sustainable Energy Reviews. 2013;18:49-54.

[9] Xu X, Hwang Y, Radermacher R. Performance comparison of R410A and R32 in vapor injection cycles. International Journal of Refrigeration. 2013;36:892-903.

[10] Marchitto A, Devia F, Fossa M, Guglielmini G, Schenone C. Experiments on twophase flow distribution inside parallel channels of compact heat exchangers. International Journal of Multiphase Flow. 2008;34:128-44.

[11] Jiao A, Zhang R, Jeong S. Experimental investigation of header configuration on flow maldistribution in plate-fin heat exchanger. Applied Thermal Engineering. 2003;23:1235-46.

[12] Nielsen KK, Engelbrecht K, Christensen D, Jensen JB, Smith A, Bahl C. Degradation of the performance of microchannel heat exchangers due to flow maldistribution. Applied Thermal Engineering. 2012;40:236-47.

[13] Chiou J. Thermal performance deterioration in crossflow heat exchanger due to the flow nonuniformity. Journal of Heat Transfer. 1978;100:580-7.

[14] Rabas T. The effect of tubeside maldistribution on the thermal performance of condensers used in multistage flash distillation plants. Desalination. 1985;55:51528.

[15] Chwalowski M, Didion D, Domanski P. Verification of evaporator computer models and analysis of performance of an evaporator coil. ASHRAE transactions. 1989;95:1229-36. 
[16] Timoney DJ, Foley PJ. Some effects of air flow maldistribution on performance of a compact evaporator with R134a. Heat Recovery Systems and CHP. 1994;14:51723.

[17] Lee J, Domanski PA. Impact of air and refrigerant maldistributions on the performance of finned-tube evaporators with R22 and R407C. Final Report, ARTI MCLR Project. 1997.

[18] Ranganayakulu C, Seetharamu K, Sreevatsan K. The effects of inlet fluid flow nonuniformity on thermal performance and pressure drops in crossflow plate-fin compact heat exchangers. International Journal of Heat and Mass Transfer. 1996;40:27-38.

[19] Ranganayakulu C, Seetharamu K. The combined effects of longitudinal heat conduction, flow nonuniformity and temperature nonuniformity in crossflow platefin heat exchangers. International communications in heat and mass transfer. 1999;26:669-78.

[20] Lalot S, Florent P, Lang S, Bergles A. Flow maldistribution in heat exchangers. Applied Thermal Engineering. 1999;19:847-63.

[21] Choi JM, Payne WV, Domanski PA. Effects of non-uniform refrigerant and air flow distributions on finned-tube evaporator performance. International Congress Refrigeration; 2003.

[22] Vist S, Pettersen J. Two-phase flow distribution in compact heat exchanger manifolds. Experimental thermal and fluid science. 2004;28:209-15.

[23] Wen J, Li Y. Study of flow distribution and its improvement on the header of platefin heat exchanger. Cryogenics. 2004;44:823-31.

[24] Wen J, Li Y, Zhou A, Zhang K, Wang J. PIV experimental investigation of entrance configuration on flow maldistribution in plate-fin heat exchanger. Cryogenics. 2006;46:37-48.

[25] Brix W, Kærn MR, Elmegaard B. Modelling refrigerant distribution in microchannel evaporators. International Journal of refrigeration. 2009;32:1736-43.

[26] Ahmad M, Berthoud G, Mercier P. General characteristics of two-phase flow distribution in a compact heat exchanger. International Journal of Heat and Mass Transfer. 2009;52:442-50.

[27] Ablanque N, Oliet C, Rigola J, Perez-Segarra C, Oliva A. Two-phase flow distribution in multiple parallel tubes. International Journal of Thermal Sciences. 2010;49:909-21.

[28] Chin WM, Raghavan VR. On the adverse influence of higher statistical moments of flow maldistribution on the performance of a heat exchanger. International Journal of Thermal Sciences. 2011;50:581-91.

[29] Nielsen KK, Engelbrecht K, Bahl C. The influence of flow maldistribution on the performance of inhomogeneous parallel plate heat exchangers. International Journal of Heat and Mass Transfer. 2013;60:432-9.

[30] Chin WM, Raghavan VR. The influence of the moments of probability density function for flow maldistribution on the thermal performance of a fin-tube heat exchanger. International Journal of Thermal Sciences. 2011;50:1942-53. 